he was sitting on a bench nnder a tree, when he suddenly fell down, as if in an epileptic fit. He was nore or less convulsed all day. There was no paralysis, and the pupils reacted well to light. Towards evening he became quieter and drowsy. The next morning he appeared relieved by quinine and castor oil, but died suddenly at 10 A.M., just twenty-four hours after the onset. The necropsy, two hours after death, showed some engorgement of the vessels of the brain, but not much effusion. The spleen weighed nine ounces, and was becoming diffluent. The blood was fluid throughout the body. There was a good deal of hypostatic congestion of the lungs. The cavities of the body felt very hot to the hand, so the following temperatures were taken Right pleural carity, $102 \cdot 2^{\circ}$; left, $1014^{\circ}$. Interior of spleen (thermometer plunged into its substance), $1032^{\circ}$; liver, $106^{\circ}$. This seems to be a genuine case of sunstroke-an accident rare in Trinidad.

CASE 3. Rupture of Coronary Artery. -- M. S-, a coloured woman, aged sixty-eight, went to bathe about 7.30 A.M. on February 20th, 1889, in one of the mountain streams. While in the water she was heard to cry out, and began to struggle. She was taken out of the water, and died a few minutes afterwards. Her previous health had been good, with the exception of some complaint of vertigo. The necropsy showed a large clot in the pericardium, enveloping the heart, and representing six or seven onnces of blood. Further examination showed a small opening in the descending branch of the posterior coronary artery. There was some discolouration of the heart muscle, with $\mathrm{a}$ small cavity in its substance, and minute nodules, apparently aneurysms, in the course of the artery. The kidneys were becoming granular. There was a calcareous plate just above the semilunar valves, and the aortic arch was very atheromatous. The brain was healthy. It would appear that the shock of the cold water on the peripheral circulation cansed sufficient increase of tension to rupture the atheromatous coronary artery.

Trinidad.

\section{CASE OF FROST-BITE, FOLLOWED BY GANGRENE, NECESSITATING AMPUTATION OF BOTH THIGHS.}

By J. Sinclair Holden, M.D.

SERToUs cases of frost-bite are so rare in this country that an account of the following case may be of interest.

William $\mathrm{C}-$, aged thirty-eight, was discharged from the navy eight years ago for misconduct, since which time he has followed the profession of an able-bodied tranı, generally keeping to country districts, and preferring any amount of exposure and hardship in the open air to seeking a night's lodging in the tramp ward of a workhouse, where he would have been compelled to pay for his accommodation by a few hours of stone-breaking in the morning. On the night of Feb. 13th, one of the coldest this winter, when the thermometer registered $22^{\circ}$ of frost and a severe snowstorm took place, this wretched man took up his quarters for the night by the side of a straw-stack in a farmyard, not two miles from the workhonse; he pulled off his boots ana wrapped his bare feet in an old waistcoat, and went to sleep. During the night snow fell heavily, and a mass tumbled off the stack and banked him in, so that he was unable to move. In the morning he attracted the attention of some of the farm labourers, who extricated him, and procured him some hot drink and wraps, and conveyed him to the Sudbury Workhouse, as his legs were so numb he could not walk. He was admitted to the infirmary, where he had every care and attention. His feet were swollen and dusky, and after a few days gangrene of the toes commenced. As this showed signs of spreading, Dr. Mason, the medical officer, asked me to see him in consultation. We considered amputation of both feet would be necessary, but to this the patient would not consent, though everything was said to explain the urgency of the operation. The following day he was more anxious about himself, and consented to submit to whatever we advised; but in the meantime the gangrene had rapidly spread and involved half of the feet, which were black and offensive, while the ankles and calves were becoming dark from venous thrombosis; his temperature was $102^{\circ}$. Though a weakly subject, and in bad condition, his only chance now lay in immediate amputation of both thighs. The arrange- ments were soon made, including antiseptic spray and accessories, and, with the assistance of Drs. Mason and King, I amputated both thighs at the lower third by anteroposterior flaps; he lost but little blood; the stumps were iodoformed and encased in carbolised gauze and wool. He rallied satisfactorily after the operation, and for severas days improved, encouraging hopes of recovery. The left stump healed by first intention; the right had some suppuration, which caused the sutures to give way and exposed the bone to a slight extent, but was quite free of any septic change. His temperature, however, always kept up, ranging from $101^{\circ}$ to $103^{\circ}$, and he did not take sufficient nourishment. Gradually he got weaker, sweats and delirium ensued, and he died twenty-four days after the operation. sudbury, Suffolk.

\section{TYPHOID FEVER.}

Br Georcie A. Branson, M.R.C.S. \&c., J.P.

THIs preventable disease has a high mortality in England, as I saw in three hospitals at home where I held resident appointments, but I regret to say an even higher death-rate probably occurs in Australia from it. The returns of cases of typhoid fever recently published by our Central Board of Health as having occurred from Dec. 1st, 1888, to Jan 24th, 1889 , are as follows:-

$\begin{array}{lrrrrrrrr}\text { Melbourne } & \ldots & \ldots & \ldots & \ldots & \ldots & 34 & \ldots \ldots & 6 \\ \text { Ballarat } & \ldots & \ldots & \ldots & \ldots & \ldots & 3 & \ldots \ldots & 2 \\ \text { Collingwood } & \ldots & \ldots & \ldots & \ldots & \ldots & 19 & \ldots \ldots & 8 \\ \text { Fitzroy } \ldots & \ldots & \ldots & \ldots & \ldots & \ldots & 16 & \ldots \ldots & 5 \\ \text { Prahran ... } & \ldots & . . & \ldots & \ldots & \ldots & 27 & \ldots \ldots & 7 \\ \text { Richmond } & \ldots & \ldots & \ldots & \ldots & \ldots & 28 & \ldots \ldots & 4 \\ \text { Sandhurst } & \ldots & \ldots & \ldots & \ldots & \ldots & 18 & \ldots \ldots & 7 \\ \text { South Melbourne } & \ldots & \ldots & \ldots & 36 & \ldots \ldots & 13\end{array}$

This statement shows a total of 181 cases with fifty-two deathis-a grievously dismaying result; and these are but the first eight towns on the list, and, with the exception of Ballarat and Sandhurst, the other six are Melbourne and its suburbs.

I was fortunately able to attend the recent delightful Medical Congress in Melbourne, where much was said about typhoid fever, but little or nothing as to its treatment; and as I have had an unusual success by adopting an almost routine line of treatment in these cases, I wish to bring it before the profession, especially since I am informed by many leading practitioners that they have never tried the drug I rely upon-veratrum viride. Of the last twentyseven cases I have treated with it, I have only lost one; and he, poor fellow, recklessly killed himself. Having doubted my diagnosis, he went by mail to Melbourne, a distance of 150 miles, where he stayed for two days mostly walking about, then came back here collapsed, but drove home ten miles in buggy over a rough road, and died three days afterwards of sheer exhaustion. The line of treatment I adopt is to begin with eight or ten grains of calomel, and order an eight-ounce mixture, containing one drachm of tincture of veratrum viride, of which the patient is to take one tablespoonful every second hour until the pulse is down to 100 beats per minute, and then to take it less frequently so as to keep it at or about 100 . I have seen three doses reduce a pulse in sever hours from 150 to below 100 , and the temperature at the same time from $105^{\circ}$ to $1025^{\circ}$. I believe veratrum viride strengthens the heart unless pushed to an excessive dose. I persuade my patients to lie, during the first fortnight, alternately on their right and left side, so as to save their backs for the later stages. I never give a purgative after the first week, but the mildest of laxatives, such as a refreshing dose of the granular citrate of magnesia; and if this does not act sufficiently I give an enema, for I have seen more thas one patient collapse from a reckless dose of castor oil. I advise frequent spongings of the body, and, if the temperature shonld go up in spite of the veratrum viride, I use antipyrin freely; but I have seen this drug produce delirium in a child, although it reduced the fever, and bromide of potassium soon removed the delirium. I never permit a typhoid patient to take any thing but milk, water, and soda water until about the third week, when I usually give brandy, and often give it freely. When the evening temperature is lown to normal and the morning temperature has been so for two days, I order other liquid food, but no meat for another month. 